\title{
Divergência genética em tomate estimada por marcadores RAPD em comparação com descritores multicategóricos
}

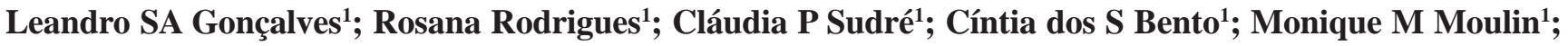 \\ Maria Luiza de Araújoº ${ }^{2}$ Rogério F Daher ${ }^{1}$; Telma Nair S Pereira ${ }^{1}$; Messias G Pereira ${ }^{1}$ \\ ${ }^{1}$ UENF-LMGV, Av. Alberto Lamego, 2000, Pq. Califórnia, 28013-620 Campos dos Goytacazes-RJ; ${ }^{2}$ Pesagro, Br 465, km 7, 23851-970 \\ Seropédica-RJ; lsagrural@yahoo.com.br
}

\section{RESUMO}

A estimativa da variabilidade genética existente em um banco de germoplasma é importante não só para a conservação dos recursos genéticos, mas também para aplicações no melhoramento de plantas. O presente trabalho teve como objetivo estudar a divergência genética entre 78 acessos de uma coleção de germoplasma de tomateiro, com base em 74 marcadores RAPD e correlacionar esses resultados àqueles da caracterização morfoagronômica realizada para 27 descritores. Foi utilizado o agrupamento hierárquico UPGMA para analisar os dados, observando-se a formação de 13 grupos. Esses grupos foram correlacionados a cinco descritores (hábito de crescimento, tipo de folha, cor do fruto, número de lóculos e formato do fruto). Alguns grupos apresentaram peculiaridades, a exemplo do grupo IV, que reuniu acessos com frutos no formato de pêra; o grupo VII com acessos resistentes a murcha-bacteriana e o grupo IX, que englobou acessos com folhas do tipo batata. As análises por bootstrap revelaram poucos agrupamentos consistentes. Houve correlação positiva e altamente significativa entre as matrizes geradas pelos 27 descritores qualitativos e pelos marcadores $\operatorname{RAPD}(t=14,02)$. A correlação de Mantel $(r=0,39)$ foi altamente significativa, porém de baixa magnitude. $\mathrm{O}$ baixo valor verificado para esta correlação sugere que ambas as etapas de caracterização (morfoagronômica e molecular) são importantes para um conhecimento mais amplo e melhor discriminação entre os acessos de tomate.

Palavras-chave: Solanum lycopersicum, recursos genéticos, UPGMA, marcadores moleculares, descritores morfológicos.

\begin{abstract}
Genetic divergence among tomato accessions using RAPD markers and its comparison with multicategoric descriptors

The estimation of genetic variability in a germplasm bank is important not only for the conservation of the genetic resources, but also for applications in plant breeding. The genetic divergence among 78 tomato accessions was studied, based on 74 RAPD markers. Also, a correlation between the molecular profile and 27 morphological and agronomic data was performed. Cluster analysis (UPGMA), used to study the data, resulted in 13 groups that were correlated with five descriptors (growth habit, leaf type, fruit color, locule number, and fruit shape). Some groups had particularities, such as group IV that assembled accessions with pear shape fruits; group VII, that clustered accessions with bacterial wilt resistance, and group IX, that gathered accessions with potato leaf type. Bootstrap analysis revealed few consistent clusters. The results showed a positive and significant correlation between the matrixes generated out of qualitative and molecular data $(\mathrm{t}=14.02)$. Mantel's correlation was highly significant, but with a low value $(r=0.39)$, which suggests that for a wise use of the germplasm bank accessions, both characterization, molecular and morphoagronomic, should be carried out.
\end{abstract}

Keywords: Solanum lycopersicum, genetic resources, UPGMA, molecular markers, morphological descriptors.

\section{(Recebido para publicação em 25 de abril de 2007; aceito em 26 de agosto de 2008)}

$\mathrm{O}$ tomateiro é uma entre as muitas espécies autógamas cultivadas que teve sua diversidade genética reduzida drasticamente. Primeiro, devido à domesticação fora do seu centro de origem e, segundo, pelo melhoramento genético que tem sido realizado ao longo dos anos com base em um número limitado de genótipos. Além disso, muitos genótipos foram perdidos ao longo do tempo, em consequiência da substituição ou do desaparecimento de espécies silvestres, cultivares obsoletas e cultivares locais (Saavedra et al., 2001). Conseqüentemente, se observa alto grau de uniformidade nas cultivares, tornando a cultura altamente vulnerável a pragas e doenças (Carelli, 2003).
Estudos de diversidade genética em tomateiro utilizando marcadores moleculares revelaram uma estreita base genética das cultivares modernas (Saavedra \& Spoor, 2002). Por isso os bancos de germoplasma são de suma importância, pois colocam à disposição dos pesquisadores ampla fonte de recursos genéticos, que podem fornecer genes que conferem adaptação a diferentes estresses abióticos e resistência a inúmeras pragas e doenças. Entretanto, os acessos conservados em bancos de germoplasma são pouco utilizados devido a uma série de dificuldades e deficiências, tais como falta de documentação, falta de descrição adequada e falta de avaliação das coleções, o que limita a ação de melhoristas (Gepts, 2006).
A caracterização e a avaliação de acessos dos bancos de germoplasma são de fundamental importância, pois contribuem para maior conhecimento destes, viabilizando a detecção de possíveis genótipos a serem utilizados em programas de melhoramento de plantas e detecção de possíveis duplicatas nos bancos de germoplasma (Valls, 1988). A presença de acessos duplicados em coleções de germoplasma aumenta o trabalho do curador e reduz o espaço disponível para conservação de outras amostras, sem contribuir para o enriquecimento da variabilidade genética (Van Hintum \& Vissen, 1995).

Para complementar as informações e aumentar a base de conhecimento ge- 
nético sobre os acessos de um banco de germoplasma, os marcadores moleculares têm sido de grande valia. Esses marcadores revelam diferenças genéticas em um maior nível de detalhamento e sem as interferências causadas pelo efeito ambiental, oferecendo vantagens em termos de discriminação e rapidez (Binneck et al., 2002). Os estudos com marcadores moleculares trazem contribuições significativas para a compreensão da diversidade genética (Spooner et al., 2005). $\mathrm{O}$ benefício principal de se usar marcadores moleculares é que estes são bons indicadores da distância genética entre acessos, por causa da sua neutralidade seletiva. Assim, os marcadores moleculares estão sendo utilizados para auxiliar o curador nas atividades de manutenção, caracterização e avaliação de germoplasma (Rao \& Riley, 1994).

Este trabalho teve como objetivos caracterizar parte do banco de germoplasma de tomateiro da UENF utilizando marcadores RAPD, quantificar a divergência genética entre acessos, identificar possíveis duplicatas e correlacionar os dados morfoagronômicos aos moleculares.

\section{MATERIAL E MÉTODOS}

$\mathrm{Na}$ caracterização molecular foram utilizados 78 acessos de Solanum lycopersicum do banco de germoplasma da Universidade Estadual do Norte Fluminense Darcy Ribeiro (UENF) (Tabela 1). Todos os acessos foram cedidos pela Empresa de Pesquisa Agropecuária do Estado do Rio de Janeiro (PesagroRio), Estação Experimental de Seropédica. Desse total, 58 acessos foram caracterizados também com base em 27 descritores morfoagronômicos (Karasawa, 2005). Nesta caracterização foram utilizados os descritores: cor e pubescência do hipocótilo, hábito de crescimento, densidade da pubescência e comprimento do internódio do caule, densidade da folhagem, tipo de folha, tipo e número de inflorescências, número de flores por inflorescência, cor da corola e do fruto imaturo, frutos por inflorescência, pubescência e forma do fruto, presença de ombro verde no fruto, cor do fruto maduro, intensidade da cor externa do fruto, cor da pele do fruto e do pericarpo, presença de fruto oco, número de locos, forma do corte transversal do fruto, da cicatriz do pistilo no fruto e do ápice do fruto, rachadura radial no fruto e rachadura concêntrica.

Os acessos de tomateiro foram semeados em bandejas de poliestireno de 128 células. Após 15 dias do semeio as mudas foram transplantadas para potes plásticos com capacidade para $0,5 \mathrm{~L}$ contendo substrato Plantmax ${ }^{\circledast}$. As plantas foram cultivadas em casa-de-vegetação, na Unidade de Apoio à Pesquisa da UENF, em Campos dos Goytacazes (RJ). Trinta e cinco dias após o semeio, amostras de 3,0 g de folhas jovens foram coletadas, identificadas e imediatamente mergulhadas em $\mathrm{N}_{2}$ líquido. Uma vez no laboratório, este material foi acondicionado em ultrafreezer a $-86^{\circ} \mathrm{C}$. Posteriormente, estas folhas foram maceradas em $\mathrm{N}_{2}$ líquido e acondicionadas em tubos de $15 \mathrm{~mL}$.

Cerca de $300 \mathrm{mg}$ de tecido macerado foram transferidos para tubos de $2,0 \mathrm{~mL}$ e imersos em $\mathrm{N}_{2}$ líquido para a extração de DNA (Daher et al., 2002). A quantificação foi realizada em géis de agarose $0,8 \%(\mathrm{p} / \mathrm{v})$ submetidos à eletroforese. Alíquotas de DNA foram aplicadas nos poços do gel ao lado de um marcador com concentração conhecida $(\lambda)$. A concentração das amostras foi estimada por comparação visual da intensidade de fluorescência das bandas do DNA $(\lambda)$. Posteriormente, o DNA foi diluído (10 $\left.\mathrm{ng} \mu \mathrm{L}^{-1}\right)$ para as reações de RAPD.

As reações de amplificação foram feitas em termociclador modelo Mastercycler gradient (Eppendorf), em $20 \mu \mathrm{L}$ contendo: $10 \mathrm{mmol} \mathrm{L}^{-1}$ Tris $\mathrm{HCl}$, $\mathrm{pH} 8,3 ; 50 \mu \mathrm{mol} \mathrm{L}^{-1} \mathrm{KCl} ; 2,4 \mathrm{mmol} \mathrm{L}^{-1}$ $\mathrm{MgCl}_{2} ; 100 \mu \mathrm{M}$ dATP, dCTP, dGTP e dTTP; 0,4 $\mu \mathrm{M}$ de iniciador; $20 \mathrm{ng}$ de DNA genômico e 0,75 unidade de Taq DNA-polimerase. Foram utilizados microtubos em que foram colocados 2 $\mu \mathrm{L}$ de DNA e, paralelamente, preparado um mix contendo todos os demais reagentes nas concentrações mencionadas, cada mix contendo um iniciador diferente. Desta solução, foram retirados $18 \mu \mathrm{L}$ e adicionados aos microtubos, totalizando os $20 \mu \mathrm{L}$ da reação. As reações foram submetidas a 45 ciclos de amplificação após desnaturação inicial a $95^{\circ} \mathrm{C}$ por 1 minuto. Cada ciclo consistiu de 1 minuto a $94^{\circ} \mathrm{C}, 1$ minuto a $36^{\circ} \mathrm{C}$ e 2 minutos a $72^{\circ} \mathrm{C}$. Ao final de 45 ciclos, foi realizada uma extensão final de 7 minutos a $72^{\circ} \mathrm{C}$. Os produtos de amplificação foram submetidos a eletroforese ( $100 \mathrm{~V}$ durante 90 minutos) em géis de agarose $1,4 \%(\mathrm{p} / \mathrm{v})$, utilizando o tampão de corrida TBE $1 \mathrm{X}$. Os géis foram corados com brometo de etídeo e fotografados sob luz UV (Eagle Eye II - Stratagene).

Efetuou-se uma triagem de iniciadores que fossem capazes de detectar polimorfismo. Para esta verificação, foram selecionados quatro acessos divergentes com base nos dados morfoagronômicos (UENF 155, UENF 166, UENF 196 e UENF 197). Considerando-se os quatro acessos, foram testados 358 iniciadores dos respectivos kits OPA, OPAA, OPAB, OPAC, OPAD, OPAH, OPB, OPC, OPD, OPE, OPG, OPI, OPK, OPN, OPO, OPT, OPW, OPV e OPX da Operon Technologies, selecionando-se como polimórficos os iniciadores OPAA 03, OPAA 04, OPAA 18, OPAB 05, OPAB 07, ОРAB 09, OPAB 14, OPAC O6, OPAH 01, OPC 08, OPC 09, OPC 11, OPC 15, OPE 06, OPE 07 , OPE 18 , OPG 16 , OPI 12, OPI 20, OPK 16, OPN 06, OPN 08, OPO 10, OPT 16, OPW 06, OPW 13 e OPV 12.

As bandas foram avaliadas visualmente em todos os acessos, considerando-se para análise apenas aquelas mais evidentes e consistentes nos 78 acessos avaliados. Foi elaborada uma matriz de dados binários correspondente à presença (1) ou ausência (0) das bandas. Para formação da matriz de dissimilaridade foi utilizado o complemento aritmético do Índice de Jaccard. A partir destes dados, foi realizado o agrupamento dos acessos utilizando o método hierárquico de UPGMA (Unweighted PairGroup Method Using an Arithmetic Average). A validação dos nós apresentados no dendrograma foi feita por meio da metodologia do bootstrap, que é um instrumento de simulação estatística que tem como princípio estudar e avaliar a estabilidade dos agrupamentos obtidos a partir de matrizes de dissimilaridade. Essa técnica consiste em compor uma 
amostra comum originada da junção das amostras individuais de cada população. A partir dessa amostra, são obtidas por reamostragem com reposição amostras do mesmo tamanho daquelas extraídas individualmente de cada população. A estatística do teste é computada e o procedimento é repetido milhares de vezes. Com os milhares de valores da estatística é possível obter uma distribuição de probabilidade empírica e efetuar testes de hipóteses e estimação de parâmetros (Lavoranti, 2003). No presente trabalho, a análise de bootstrap foi conduzida considerando-se 1000 reamostragens.

Com base nos dados moleculares, foi realizada uma comparação com os cinco descritores importantes na discriminação dos acessos na etapa de caracterização morfoagronômica. Com exceção do descritor "tipo de folha", os outros quatro descritores foram apontados pelos melhoristas como sendo de importância para a caracterização dos acessos dos bancos de germoplasma (Rodrigues et al., 2002).

No intuito de comparar os resultados moleculares aos resultados de caracterização morfoagronômica já disponíveis, foi necessária a transformação dos dados qualitativos obtidos a partir dos 27 descritores morfoagronômicos em dados binários, para a realização da análise de dissimilaridade por meio do complemento aritmético do índice de Jaccard. Obtidas as matrizes de dissimilaridade morfoagronômica e molecular, ambas foram comparadas pelo teste de correlação de Mantel e pelo teste t. Todos os dados foram analisados pelo programa GENES (Cruz, 2006), com exceção do dendrograma obtido pelo método UPGMA, gerado com auxílio do programa STATISTICA (1995).

\section{RESULTADOS E DISCUSSÃO}

Cada iniciador produziu bandas de intensidade variável, facilmente detectadas, e bandas inespecíficas que foram descartadas. Os 27 iniciadores utilizados produziram 132 bandas. Destas, 74 foram polimórficas, ou seja, em média, cada iniciador gerou 2,74 bandas polimórficas. O número total de bandas polimórficas por iniciador variou de 1 a
6, sendo os iniciadores OPE 18 e OPG 16 os mais polimórficos, gerando seis bandas cada um.

Detectou-se diversidade genética entre os acessos de tomateiro estudados com base na técnica do RAPD, conforme já descrito em outros trabalhos com tomateiro (Williams \& St. Clair, 1993; Villand et al., 1998; Noli et al., 1999; Carelli et al., 2006). Utilizando a matriz de Jaccard, identificou-se como mais distantes os acessos UENF 202 e UENF 1662 , com distância de 0,34 , enquanto os acessos UENF 1667 e UENF 1701 foram os mais similares, com distância de 0,01. A distância média observada entre os acessos foi $0,19( \pm 0,04)$. Carelli et al. (2006) analisando 35 acessos de tomateiro com 20 iniciadores RAPD obtiveram uma distância que variou entre 0,43 e 0,82 , com média de 0,65 ( \pm 0,09). Entretanto, Villand et al. (1998) analisaram 96 acessos de tomateiro com 41 iniciadores RAPD e obtiveram distâncias que variaram entre 0,01 e 0,50, com média de $0,16( \pm 0,08)$. Essas diferenças se devem provavelmente à origem dos acessos estudados.

Um corte realizado na distância de 0,18 , considerando-se o ponto de mudança abrupta, possibilitou a formação de 13 grupos (Figura 1). O grupo I foi constituído pelo maior número de acessos, totalizando 51 acessos, ou seja, $65 \%$ do total (Tabelas 1 e 2). Este foi o grupo que apresentou o maior número de bandas polimórficas, evidenciando uma maior variabilidade genética em relação aos demais grupos formados. Considerando-se o fato desse grupo apresentar uma alta variabilidade intra-grupo e reunir um número grande de acessos, optou-se por subdividi-lo em dois subgrupos. O subgrupo I.A foi constituído por 26 acessos e o subgrupo I.B foi formado por 25 acessos. Ainda assim, foi possível notar que os subgrupos formados tiveram uma maior presença de bandas polimórficas, associadas a um maior número de acessos agrupados em relação a todos os demais grupos.

Embora formados exclusivamente a partir dos perfis moleculares, os grupos apresentaram algumas características fenotípicas peculiares. Em relação ao hábito de crescimento, observou-se que o crescimento indeterminado foi predo- minante nos acessos estudados, com exceção dos acessos UENF 160 e UENF 157 (Tanzimech), de crescimento determinado e semi-determinado, respectivamente. $\mathrm{O}$ acesso UENF 157 permaneceu isolado no grupo X. Para o tipo de folha, três acessos (UENF 209, UENF 222 e UENF 224), cujas plantas foram as únicas a possuírem folhas do tipo batata, característica que determina a variedade botânica grandifolium, ficaram reunidos no grupo IX.

O grupo VII reuniu os acessos UENF 1662 (C38 D Novo) e UENF 1663 (Santa Bárbara) provenientes de um programa de melhoramento visando resistência a Ralstonia solanacearum (murchabacteriana) conduzido na Amazônia (Cheng \& Chu, 2002). Embora o grupo possa ser caracterizado pela sua resistência e por outros caracteres similares como a presença de plantas de hábito de crescimento indeterminado, folhas do tipo normal e frutos vermelhos e multiloculares, em relação ao formato do fruto, o acesso C38 D Novo produziu frutos no formado globular, enquanto o acesso Santa Bárbara produziu frutos no formato cilíndrico alongado. O grupo VIII reuniu dois acessos (Seco e Roquesso) que entre as similaridades produziram frutos vermelhos, multiloculares e de formato globular. Esses acessos são provenientes de coletas junto a pequenos produtores e tratase de sementes conhecidas na literatura como heirloom, ou seja, mantidas há muitas décadas por produtores.

Noli et al. (1999), utilizando de marcadores RAPD, não conseguiram distinguir cultivares de tomate com características fenotípicas distintas. No presente estudo foi possível identificar grupos contendo acessos com características fenotípicas idênticas entre si e diferentes dos demais acessos de outros grupos. Por exemplo, os grupos VII e XII reuniram respectivamente os acessos resistentes a Ralstonia solanacearum e os acessos com frutos amarelos. Por outro lado, o único acesso de hábito determinado (UENF 160) não pode ser distinguido de outros de hábito indeterminado com base nos marcadores RAPD.

Ramos (2003) descreve que são considerados ramos consistentes em uma 
Tabela 1. Acessos de tomate caracterizados com marcadores RAPD e agrupados pelo método UPGMA (Tomato accessions characterized using RAPD markers and clustered by UPGMA method.) Campos dos Goytacazes, UENF, 2007.

\begin{tabular}{|c|c|c|c|c|c|c|c|c|c|c|c|}
\hline Acesso & $\begin{array}{c}\mathbf{N}^{\circ} \\
\text { UENF }\end{array}$ & Nome comum & Grupo & Acesso & $\begin{array}{c}\mathbf{N}^{\circ} \\
\text { UENF }\end{array}$ & Nome comum & Grupo & Acesso & $\begin{array}{c}\mathbf{N}^{\circ} \\
\text { UENF }\end{array}$ & Nome comum & Grupo \\
\hline 1 & 104 & - & IA & 27 & 179 & Red Jacket & IB & 53 & 211 & Cornell 54-17 & $\mathrm{Vl}$ \\
\hline 2 & 140 & S.C. Yokota & IA & 28 & 180 & VR superior & IB & 54 & 212 & Roma & IA \\
\hline 3 & 154 & Clinton & II & 29 & 182 & ES-58 & IA & 55 & 213 & Persimmon type & IA \\
\hline 4 & 155 & Indiana - 73 & IB & 30 & 183 & Paul Bynuan & IB & 56 & 215 & PI-255839 & IB \\
\hline 5 & 156 & Nuova Super roma & IA & 31 & 185 & $W$-139-1-2-1-1-1 & IA & 57 & 217 & WV-289-1-4-1 & V \\
\hline 6 & 157 & Tanzimech & $x$ & 32 & 186 & VR Wisconsin & IA & 58 & 218 & Manelee & IA \\
\hline 7 & 158 & Todo Royo & IB & 33 & 187 & PI-95588 CGS & IA & 59 & 219 & Red top & IB \\
\hline 8 & 159 & UC-105J & III & 34 & 188 & Heinz 14451 VF & IA & 60 & 221 & WV Rutgers & $\mathrm{A}$ \\
\hline 9 & 160 & OSU-460-1 & IA & 35 & 189 & VF-14 & IB & 61 & 222 & ACC pigment line & IX \\
\hline 10 & 161 & VR Sugar & IB & 36 & 190 & $\mathrm{PI}-262910$ CGS & IA & 62 & 223 & $\mathrm{Pl}-105342$ & $X I$ \\
\hline 11 & 162 & Early Chabham & IB & 37 & 193 & Heinz 2439 & IA & 63 & 224 & Manzaha & IX \\
\hline 12 & 163 & Pearson & IB & 38 & 194 & Acano & IB & 64 & 225 & VR Pitnic hard & IB \\
\hline 13 & 165 & VR Red Cloud & IB & 39 & 195 & Valians & IA & 65 & 216 & Terusend & IA \\
\hline 14 & 166 & Starfine & III & 40 & 196 & Bongned & IA & 66 & 1662 & C 38 D Novo & VII \\
\hline 15 & 167 & Sweft & IB & 41 & 197 & Sundwarf 4 & V & 67 & 1663 & Santa Barbara & VII \\
\hline 16 & 168 & W-334-1-2-1 & IV & 42 & 199 & Utah 4 & IA & 68 & 1664 & Seco & VIII \\
\hline 17 & 169 & PI-280597 & IB & 43 & 200 & Improved Garden & IA & 69 & 1665 & Duradouro Vermelho & $\mid \mathrm{A}$ \\
\hline 18 & 170 & Hand warf & IA & 44 & 201 & - & IV & 70 & 1666 & Roqueso & VIII \\
\hline 19 & 171 & C-52 & IB & 45 & 202 & $\mathrm{KC} \mathrm{46j2 \textrm {j } 2}$ & XIII & 71 & 1667 & Cereja FM & IB \\
\hline 20 & 172 & W-252-1-1-1 & IB & 46 & 204 & Cornell 61-56 & IA & 72 & 1668 & Comprido Vermelho & IB \\
\hline 21 & 173 & Hoytlille & IB & 47 & 205 & Porte & IB & 73 & 1669 & Pêra & IV \\
\hline 22 & 174 & Hotset & II & 48 & 206 & PI-255829 CGS & IA & 74 & 1700 & Dedo de Dama & IB \\
\hline 23 & 175 & $1260-1-1$ & $\mathrm{XI}$ & 49 & 208 & V 641 & IA & 75 & 1701 & Cereja & IB \\
\hline 24 & 176 & $\mathrm{PI}-280060$ & IA & 50 & 209 & Short Stem Boone & IX & 76 & 1702 & Gauchinho & XII \\
\hline 25 & 177 & Bould Mountain & IB & 51 & 210 & C-49-59 & $\mathrm{XI}$ & 77 & 1703 & Comprido Amarelo & XII \\
\hline 26 & 178 & Early Pak & XII & 52 & $210 B$ & C-49-59 & IV & 78 & 1704 & Pomodoro & XII \\
\hline
\end{tabular}

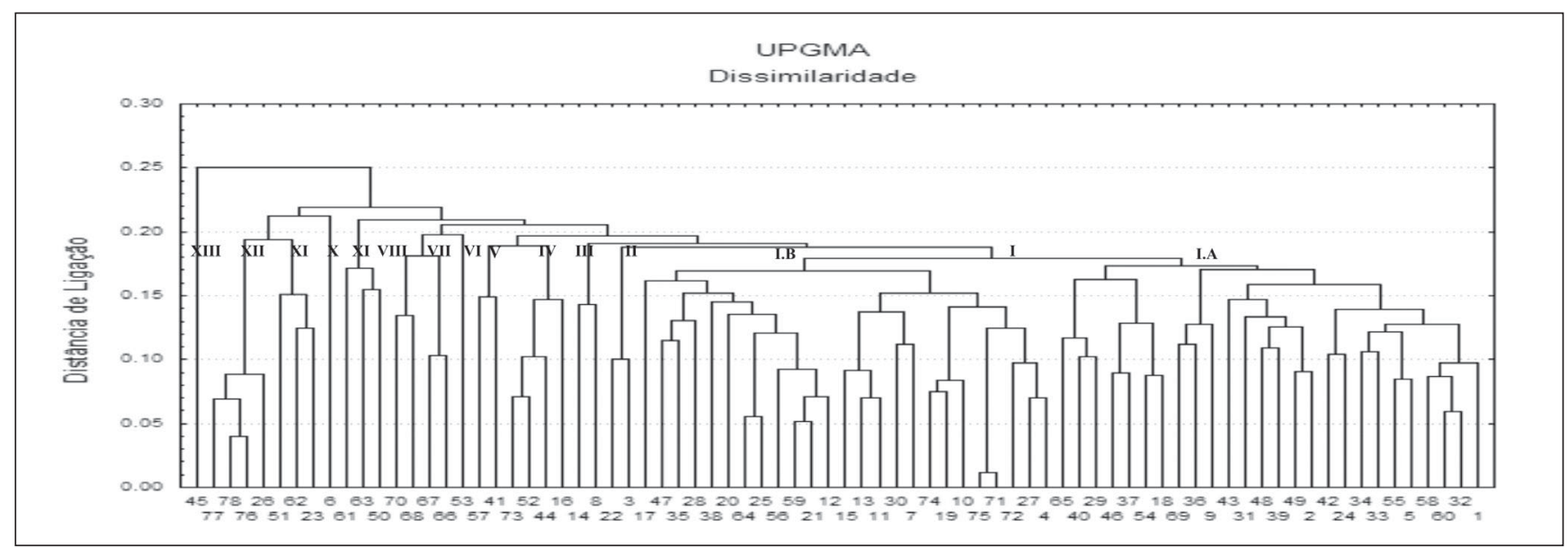

Figura 1. Dendrograma obtido pelo método UPGMA a partir das medidas de dissimilaridade genética entre 78 acessos de tomate caracterizados por marcadores RAPD (Dendrogram of genetic dissimilarity among 78 tomato accessions characterized with RAPD markers, based on the UPGMA method). Campos dos Goytacazes, UENF, 2007.

análise de agrupamentos, para a variação entre locos, aqueles com valores de bootstrap superiores a $60 \%$. Com base nessa premissa, no presente trabalho os agrupamentos referentes aos acessos UENF 1667 e UENF 1701 (99,4\%, subgrupo IB); UENF 1702 e UENF 1704 (64,5\%, grupo XII); UENF 177 e UENF 225 (67,9\%, subgrupo IB); UENF 155 e UENF 179 (62,7\%, subgrupo IB), UENF 1702 e UENF 178 (82,6\%, grupo XII); UENF 1662 e
UENF 1663 (61,8\%, grupo VII); UENF 104 e UENF 140 (100\%, subgrupo IA), e UENF 104 e UENF 155 (80,1\%, grupo I) podem ser considerados consistentes. Os outros ramos formados devem ser considerados pouco consistentes, 
Tabela 2. Identificação dos grupos e subgrupos, número de acessos por grupo e subgrupo, número de iniciadores, número de bandas polimórficas e características fenotípicas predominantes em cada grupo de acessos de tomate (Group and subgroup identification, number of accessions in each group or subgroup, number of polymorphic primers and bands, and predominant phenotypic characters in each group of tomato accessions). Campos dos Goytacazes, UENF, 2007.

\begin{tabular}{|c|c|c|c|c|}
\hline $\begin{array}{l}\text { Grupol } \\
\text { Subgrupo }\end{array}$ & $\begin{array}{l}\mathbf{N}^{\circ} \text { de } \\
\text { acessos }\end{array}$ & $\begin{array}{c}\mathrm{N}^{\circ} \text { de } \\
\text { iniciadores } \\
\text { polimórficos }\end{array}$ & $\begin{array}{c}\mathrm{N}^{\circ} \text { de } \\
\text { bandas } \\
\text { polimórficas }\end{array}$ & Características fenotípicas predominantes da classe ${ }^{2}$ \\
\hline $\mathrm{I}$ & 51 & 25 & 50 & \\
\hline I.A & 26 & 19 & 38 & Folha normal e frutos vermelhos \\
\hline I.B & 25 & 17 & 35 & Hábito indeterminado, folha normal e frutos vermelhos \\
\hline II & 2 & 9 & 14 & Hábito indeterminado, folha normal e frutos vermelhos, triloculares e globulares \\
\hline III & 2 & 12 & 21 & $\begin{array}{l}\text { Hábito indeterminado, folha normal e frutos vermelhos, biloculares e levemente } \\
\text { achatados }\end{array}$ \\
\hline IV & 4 & 19 & 23 & Hábito indeterminado, folha normal e frutos biloculares \\
\hline V & 2 & 10 & 17 & Hábito indeterminado, folha normal e frutos vermelhos, multiloculares e globular \\
\hline $\mathrm{VI}$ & 1 & - & - & Hábito indeterminado, folha normal e fruto vermelho, bilocular e globular \\
\hline VII & 2 & 8 & 13 & $\begin{array}{l}\text { Hábito indeterminado, folha normal e frutos vermelhos e multiloculares, e } \\
\text { resistência a Ralstonia solanacearum }\end{array}$ \\
\hline VIII & 2 & 9 & 15 & Hábito indeterminado, folha normal e frutos vermelhos, multiloculares e globular \\
\hline $\mathrm{IX}$ & 3 & 19 & 29 & Hábito indeterminado e folha batata \\
\hline $\mathrm{x}$ & 1 & - & - & Hábito semi-determinado, folha normal e frutos vermelhos, multiloculares eglobular \\
\hline $\mathrm{XI}$ & 3 & 18 & 27 & Hábito indeterminado e folha normal \\
\hline XII & 4 & 11 & 12 & Hábito indeterminado, folha normal e frutos amarelos e biloculares \\
\hline XIII & 1 & - & - & $\begin{array}{l}\text { Hábito indeterminado, folha normal e frutos vermelhos biloculares e cilíndrico } \\
\text { alongado }\end{array}$ \\
\hline
\end{tabular}

${ }_{1 / \text { Para identificação dos acessos, consulte a Tabela } 1 \text { (for accession identification, see Table 1); }{ }^{2} \text { Características fenotípicas predominantes }}$ nos grupos, relativas aos descritores hábito de crescimento, tipo de folha, coloração dos frutos, número de lóculos e formato do fruto, com base em Karasawa (2005). (Phenotypic characters predominant in the groups in relation to the descriptors growth habit, leaf type, fruit color, number of locules, and fruit shape, based on Karasawa, 2005).

devido à variação existente na informação produzida pelos locos, ou seja, mudando-se os locos, estes grupos não são necessariamente reproduzidos. Em outros trabalhos, por exemplo, no estudo de diversidade genética em uma população de 148 híbridos de Murcott e laranja Pêra, por meio da utilização de marcadores fAFLP e RAPD, Bastianel et al. (2006) também verificaram pouca consistência estatística pela análise de bootstrap entre os grupos formados. Creste et al. (2005) investigando o relacionamento genético entre quinze acessos originários do Brasil de Arachis e Heteranthae utilizando marcadores RAPD, mostraram que a análise de bootstrap dividiu os acessos em dois grupos consistentes. $\mathrm{O}$ primeiro grupo conteve os acessos Arachis e, o segundo, os acessos de Heteranthae. Entretanto, deve-se ressaltar que esse resultado foi obtido com acessos de duas espécies diferentes, enquanto no presente estudo os acessos estudados são de uma única espécie.

Os ramos consistentes indicam a coerência dos resultados obtidos e, em termos de divergência entre os acessos, demonstram que existe uma grande probabilidade de que os grupos formados reúnam de fato os genótipos mais similares. Esse fato tem implicações para o melhoramento de plantas, pois os acessos mais similares em geral não são utilizados em cruzamentos, já que, nesses casos, a produção de indivíduos com alto valor heterótico não é esperada entre genitores muito próximos geneticamente. Por outro lado, espera-se a obtenção de maior variabilidade com a recomendação de cruzamentos entre acessos mais divergentes.

A comparação entre os resultados do estudo da diversidade genética realizada com base em 27 descritores morfoagronômicos qualitativos e os marcadores RAPD demonstrou, para os acessos em estudo, padrões de dissimilaridade distintos entre as matrizes geradas pelos dados qualitativos e moleculares. Com base na matriz morfoagronômica os acessos mais divergentes foram UENF 160 e UENF 224 , distantes 0,66 , enquanto os aces- sos UENF 199 e UENF 219 foram os mais similares com uma distância de 0,04. Em média a distância observada foi de 0,37 ( $\pm 0,0941)$. Em contrapartida, na matriz gerada a partir de dados moleculares foi observado que os acessos mais divergentes foram UENF 160 e UENF 178 com uma distância de 0,32 , enquanto os acessos UENF 169 e UENF 219 foram os mais similares com uma distância de 0,05. Em média a distância observada foi de $0,1927( \pm 0,0424)$ para dados moleculares.

Apesar das divergências em similaridade, houve correlação positiva e altamente significativa entre as matrizes de distância formadas pelas características morfoagronômicas e pelos marcadores RAPD $(t=14,02)$. Isso significa que os resultados da caracterização morfoagronômica geraram matrizes de distância que se assemelham à matriz gerada pela caracterização molecular. Em relação à correlação de Mantel, obteve-se um valor de correlação relativamente baixo $(r=0,39)$, que pode ser atribuído às diferenças ineren- 
tes aos marcadores fenotípicos e moleculares. Enquanto os marcadores RAPD cobrem uma proporção maior do genoma, incluindo regiões não codantes, os marcadores fenotípicos são a expressão exclusiva das regiões codantes. Conseqüentemente, o perfil molecular pode representar regiões não correlatas com as características fenotípicas estudadas. O baixo valor verificado para esta correlação sugere que ambas as etapas de caracterização (morfoagronômica e molecular) são importantes para o conhecimento mais amplo e melhor discriminação entre os acessos do banco de germoplasma. Resultado semelhante foi observado por Kamada (2006), que correlacionou caracteres fenotípicos com marcadores RAPD em quatro populações de fáfia (Pfaffia glomerata). Neste trabalho foi observada correlação altamente significativa pelo teste $\mathrm{Z}$, entretanto com valor baixo de correlação $(0,28)$, concluindo-se que não é recomendável utilizar apenas um tipo de marcador, seja ele fenotípico ou molecular, para estimar a diversidade no aspecto qualitativo, uma vez que as correlações entre as distâncias genéticas foram baixas.

Entretanto, outros relatos indicam que é possível observar alta correlação entre dados morfoagronômicos e moleculares. Por exemplo, Garcia et al. (1998), trabalhando com 32 linhas melhoradas de melão, correlacionaram duas matrizes, sendo uma formada por 115 bandas polimórficas obtidas através da técnica de RAPD e, a outra, por 24 características agronômicas. Os autores obtiveram uma correlação de $79 \%$ pelo teste de Mantel entre as duas matrizes estudadas.

Esta aparente discrepância entre resultados pode ser justificada pelas características de cada espécie estudada, pelo tipo de descritor morfoagronômico utilizado na caracterização e pelo número de iniciadores para os quais se verificou polimorfismo. A constatação da variação entre os valores obtidos para a correlação entre as características demonstra a atenção que os curadores dos bancos de germoplasma devem ter para a caracterização mais abrangente dos acessos, conduzindo diversas etapas de caracterização e considerando o maior número possível de descritores.

No caso do tomateiro, espécie autógama em que é possível não só obter novas linhagens com características superiores, mas também explorar agronomicamente o híbrido $\mathrm{F}_{1}$, é importante não só conhecer a divergência genética com base em marcadores moleculares, mas também conhecer as características fenotípicas de interesse para produção agrícola. Dessa forma, a análise conjunta desses caracteres pode permitir uma visão mais abrangente e uma utilização mais eficiente da coleção de germoplasma.

\section{AGRADECIMENTOS}

Os autores agradecem à Faperj, pela concessão da bolsa de mestrado ao primeiro autor.

\section{REFERÊNCIAS}

BASTIANEL M; OLIVEIRA AC; CRISTOFANI M; MACHADO MC. 2006. Diversidade genética entre híbridos de laranja-doce e tangor 'Murcott' avaliada por fAFLP e RAPD. Pesquisa Agropecuária Brasileira 41: 779-784.

BINNECK E; NEDEL JL; DELLAGOSTIN OA. 2002. Análise de RAPD na identificação de cultivares: uma metodologia útil? Revista Brasileira de Sementes 24: 183-196.

CARELLI BP 2003. Estimativa de variabilidade genética em acessos crioulos e cultivares comerciais de tomate (Lycopersicum esculentum Mill.). São Carlos: UFSCar. 100p (Tese doutorado).

CARELLI BP; GERALD LTS; GRAZZIOTIN FG; ECHEVERRIGARAY S. 2006. Genetic diversity among Brazilian cultivars and landraces of tomato Lycopersicum esculentum Mill. revealed by RAPD markers. Genetic Resources and Crop Evolution 53: 395-400.

CHENG SS; CHU EY. 2002. 'Pará Belo' um clone do tomateiro adaptado à Amazônia Oriental. Horticultura Brasileira 20: 516-519.

CRESTE S; TSAI SM; VALLS JFM; GIMENES MA; LOPES CR. 2005. Genetic characterization of Brazilian annual Arachis species from sections Arachis and Heteranthae using RAPD markers. Genetic Resources and Crop Evolution 52: 1079-1086.

CRUZ CD. 2006. Programa Genes: análise multivariada e simulação. Viçosa: UFV. 175p.

DAHER RF; PEREIRA MG; TUPINAMBA EA; AMARAL JUNIOR AT; ARAGAO WM; RIBEIRO FE; OLIVEIRA LO; SAKIYAMA NS. 2002. Assessment of coconut tree genetic divergence by compound sample RAPD marker analysis. Crop Breeding and Applied Biotechnology 3: 431-438.
GARCIA E; JAMILENA M; ALVAREZ JI; ARNEDO T; OLIVER JL; LOZANO R. 1998. Genetic relationships among melon breeding lines revealed by RAPD markers and agronomic traits. Theoretical and Applied Genetics 96: 878-885.

GEPTS P. 2006. Plant genetic resources conservation and utilization: the accomplishments and future of a societal insurance policy. Crop Science 46: 2278-2292.

KAMADA T. 2006. Avaliação da diversidade genética de populações de fáfia (Pfaffia glomerata (Spreng.) Pedersen) por RAPD, caracteres morfólogicos e teor de betaecdisona. Viçosa: UFV. 106p (Tese doutorado).

KARASAWA M. 2005. Divergência genética com base em caracterização morfoagronômica e avaliação para resistência à mancha bacteriana em tomateiro. Campos dos Goytacazes: UENF. $123 p$ (Tese doutorado).

LAVORANTI OJ. 2003. Estabilidade e adaptabilidade fenotípica através da reamostragem "Bootstrap" no modelo AMMI. Piracicaba: ESALQ. 166p (Tese doutorado).

NOLI E; CONTI S; MACCAFERRI M; SANGUINETI MC. 1999. Molecular characterization of tomato cultivars. Seed Science and Technology 27: 1-10.

RAMOS SRR. 2003. Divergência genética baseada em marcadores moleculares AFLP e indicação de coleção nuclear de Curcubita moschata para o nordeste do Brasil. Campos dos Goytacazes: UENF. 102p (Tese doutorado).

RAO VR; RILEY KW. 1994. The use of biotechnology for conservation and utilization of plant genetic resources. Plant Genetic Resources Newsletter 97: 3-20.

RODRIGUES R; RAMOS SRR; SUDRÉ CP; KARASAWA M; RIVA EM; PEREIRA TNS. 2002. Indicação preliminar de descritores relevantes para o melhoramento do tomateiro. In: CONGRESSO BRASILEIRO DE OLERICULTURA, 42. Resumos... Uberlândia: SOB (CD-ROM).

SAAVEDRA G; SPOOR W; HARRIER L. 2001. Molecular markers and genetic base broadening in Lycopersicum spp. Acta Horticulturae 546: 503-507.

SAAVEDRA G; SPOOR W. 2002. Genetic base broadening in autogamous crops: Lycopersicum esculentum Mill. as a model. Managing Plant Genetic Diversity 443: 291299.

SPOONER D; VAN TREUREN R; DE VICENT MC 2005. Molecular markers for genebank management. IPGRI. Disponível em http:/ www.ipgri.cgiar.org/publications/pdf/ 1082.pdf. Acessado em 20 de fevereiro de 2007 (Technical Bulletin No. 10)

STATISTICA 1995. Programa Statistica for Windows (versão 5.0). Tulsa: StatSoft Inc.

VAN HINTUM JIT; VISSEN DL. 1995. Duplication within and between germplasm collections II. Duplication in four European barley collections. Genetic Resources and Crop Evolution 42: 135-145. 
VALLS JFM. 1988. Caracterização morfológica, reprodutiva e bioquímica de germoplasma. In: ENCONTRO SOBRE RECURSOS GENÉTICOS, 1. Anais... Jaboticabal: FCAV. p. $106-120$.
VILLAND J; SKROCH PW; LAI T; HANSON P; KUO C.G; NIEMHUIS J. 1998. Genetic variation among tomato accessions from primary and secondary centers of diversity. Crop Science 38: 1339-1347.
WILLIAMS CE; ST CLAIR DA. 1993. Phenetic relationships and levels of variability detected by restriction fragment length polymorphism and random amplified polymorphic DNA analysis of cultivared and wild accessions of Lycopersicum esculentum. Genome 36: 619-630. 